\title{
Photocatalytic Hydrogen Production from Water on Ga, Sn-doped ZnS under Visible Light Irradiation
}

\author{
Leny Yuliati ${ }^{1, a^{*}}$, Melody Kimi ${ }^{2,3, b}$ and Mustaffa Shamsuddin ${ }^{3, c}$ \\ ${ }^{1}$ Ibnu Sina Institute for Fundamental Science Studies, \\ Universiti Teknologi Malaysia, 81310 UTM Johor Bahru, Johor, Malaysia \\ ${ }^{2}$ Department of Chemistry, Faculty of Science, \\ Universiti Teknologi Malaysia, 81310 UTM Johor Bahru, Johor, Malaysia \\ ${ }^{3}$ Centre for Pre-University Studies, Universiti Malaysia Sarawak, \\ 94300 Kota Samarahan, Sarawak, Malaysia \\ a*leny@ibnusina.utm.my, ${ }^{b}$ kmelody@preuni.unimas.my, ${ }^{c}$ mustaffa@kimia.fs.utm.my
}

Keywords: $\mathrm{Ga}(0.1), \mathrm{Sn}(x)-\mathrm{ZnS}$, photocatalyst, dopant, hydrogen, visible light

\begin{abstract}
Zinc sulfide ( $\mathrm{ZnS})$ has been reported to act as a photocatalyts to reduce water to hydrogen. However, $\mathrm{ZnS}$ could not work under visible light irradiation due to its large band gap energy. In order to improve the performance of $\mathrm{ZnS}, \mathrm{Ga}$ and $\mathrm{Sn}$ were doped to $\mathrm{ZnS}$. The series of $\mathrm{Ga}(0.1), \mathrm{Sn}(x)-\mathrm{ZnS}$ with various amounts of $\mathrm{Sn}(x)$ was prepared by hydrothermal method. XRD patterns suggested that the addition of Ga might reduce the crystallinity of $\mathrm{ZnS}$, suggesting that Ga might inhibit the crystal growth or agglomeration of $\mathrm{ZnS}$. On the other hand addition of Sn did not much affect the structure of the $\mathrm{Ga}(0.1)-\mathrm{ZnS}$. The DR UU-visible spectra confirmed the red shift of the absorption edge with the addition of Ga due to the reduced band gap energy, while the addition of Sn did not much shift the absorption edge of the Ga(0.1)-ZnS to longer wavelength. FESEM images showed that all the prepared samples have sphere-shaped particles and no remarkable change was observed with the addition of $\mathrm{Ga}$ or $\mathrm{Sn}$. The photocatalytic hydrogen production from water was carried out at room temperature in the presence of sacrificial agent under visible light irradiation. While $\mathrm{ZnS}$ did not show activity under visible light, all the prepared $\mathrm{Ga}(0.1)-\mathrm{ZnS}$ and $\mathrm{Ga}(0.1), \mathrm{Sn}(x)-\mathrm{ZnS}$ samples exhibited photocatalytic activity for hydrogen production. The highest hydrogen production was achieved on $\mathrm{Ga}(0.1), \mathrm{Sn}(0.01)-\mathrm{ZnS}$, which activity was $c a$. three times higher than that of the single doped $\mathrm{Ga}(0.1)-\mathrm{ZnS}$. This study clearly showed that $\mathrm{Sn}$ acted as a good co-dopant to increase the photocatalytic activity of $\mathrm{Ga}(0.1)-\mathrm{ZnS}$ for hydrogen production from water under visible light irradiation.
\end{abstract}

\section{Introduction}

Hydrogen is one of the cleanest energy since it does not involve carbon emission. In order to sustain the production of hydrogen, the use of both renewable source and sustainable process must be concerned. Photocatalytic water splitting would be one of the best approaches to produce hydrogen $[1,2]$ using renewable water source and sustainable photocatalytic process, which only requires photocatalyst, light, and mild conditions such as room temperature. Due to the strong demand to utilize solar light, which consists of large portion of visible light region, the development of visible light-active photocatalysts has been recognized as the important approach in photocatalysis field nowadays. In this work, UV-active zinc sulfide (ZnS) was modified so that it could work under visible light irradiation.

$\mathrm{ZnS}$ is one of the reported photocatalysts for hydrogen production from water in the presence of sacrificial agents [3, 4]. It has been reported that the high activity of $\mathrm{ZnS}$ can be achieved even without addition of co-catalyst, due to the high conduction band of $\mathrm{ZnS}$ and its rapid generation of electron-hole pairs to reduce water to hydrogen. However, unfortunately, the large band gap energy has restricted the use of $\mathrm{ZnS}$ only within the UV light region. Therefore, the modification of $\mathrm{ZnS}$ is highly required to improve its performance under visible light irradiation. Doping of $\mathrm{ZnS}$ would be one of the best methods to reduce the band gap energy without changing the high conduction band 